\title{
Peningkatan Mutu Pendidikan melalui Penerapan Total Quality Management dalam Program Akreditasi Sekolah
}

\author{
Lailatul Azizah*, Silvia Witri \\ Universitas Islam Negeri Sunan Kalijaga Yogyakarta \\ *Email korespondensi: 1ailazizah30@yahoo.com
}

\begin{abstract}
Improving the quality of education is a problem that is still experienced by many educational institutions. To improve the quality of education, institutions need a system to help achieve quality education quality. So this study aims to analyze the application of Total Quality Management in the school accreditation program as an effort to improve the quality of education. This research is a literature study by taking data from several books and literature. This data collection technique uses documentation techniques and data analysis techniques using critical analysis which is interesting from several research documents. The results of this study indicate that improving the quality of education is carried out by implementing Total Quality Management. Total Quality Management is carried out by continuous improvement, determining quality standards, changing culture, changing organizations, maintaining relationships with customers and focusing on customer satisfaction. and have a commitment to change.
\end{abstract}

Keywords: Total Quality Management, Accreditation, Education Quality.

\begin{abstract}
Abstrak
Peningkatan mutu pendidikan menjadi permasalahan yang masih banyak dialami di lembaga pendidikan. Untuk meningkatkan mutu pendidikan tersebut lembaga memerlukan sistem untuk membantu tercapainya mutu pendidikan yang berkualitas. Jadi adanya penelitian ini bertujuan untuk menganalisis penerapan Total Quality Management dalam program akreditasi sekolah sebagai upaya meningkatkan mutu pendidikan. Penelitian ini merupakan penelitian studi pustaka dengan mengambil data dari beberapa buku dan literatur. Teknik pengumpulan data ini menggunakan teknik dokumentasi dan teknik analisis data menggunakan analisis kritis yang menarik dari beberapa dokumen-dokumen penelitian. Hasil penelitian ini menunjukkan bahwa dalam peningkatan mutu pendidikan dilakukan melalui menerapkan Total Quality Management. Total Quality Management dilakukan dengan cara perbaikan secara terus-menerus, menentukan standar mutu, perubahan kultur, perubahan organisasi, dan mempertahankan hubungan dengan pelanggan serta memfokuskan kepuasan pelanggan. dan memiliki komitmen dalam perubahan.
\end{abstract}

Kata Kunci: Total Quality Management, Akreditasi, Mutu Pendidikan. 


\section{A. Pendahuluan}

Pendidikan merupakan faktor utama yang membentuk suatu kepribadian manusia dan dipandang sebagai upaya dalam mencerdaskan kehidupan bangsa yang mampu megembangkan manusia yang beriman, berbudi pekerti luhur dan memiliki pengetahuan (Musfah, 2015). Kepribadian manusia sangat dipengaruhi oleh seberapa kuat pendidikan itu diperoleh. Kecerdaan suatu bangsa juga ditentukan oleh faktor pendidikan. Dengan demikian, maju mundurnya suatu bangsa dipengaruhi oleh pendidikan guna membentuk kepribadaian dan kecerdasan bangsa yang bermutu.

Sebagai salah satu Bangsa yang bermutu, pendidikan harus ditempatkan sebagai sisi penting dalam kebijakan peningkatan mutu di satuan pendidikan. karena mutu memiliki arti kemampuan yang dimiliki oleh suatu produk atau jasa yang dapat memenuhi kebutuhan atau harapan, kepuasan pelanggan dalam pendidikan. (Fattah, 2013). Mutu juga dapat diartikan sebagai gambaran dan karakteristik menyeluruh jasa pelayanan pendidikan secara internal maupun eskternal yang menunjukan kemampuanya dalam memuaskan kebutuhan yang diharapkan atau yang tersirat mencakup iput, proses, dan output pendidikan (Sagala, 2013).

Peraturan Menteri Pendidikan Nasional tentang Sistem Penjaminan Mutu Pendidikan Nomor 63 Tahun 2009 menegaskan adanya kebijakan peningkatan mutu di sekolah dapat dilakukan dengan proses akreditasi. Hal ini menunjukkan bahwa kebijakan pemerintah dalam akreditasi perlu disiapkan karena memiliki makna penting dalam membangun bangsa. Akreditasi merupakan proses untuk menilai kinerja terhadap kelayakan program yang terdapat dalam satuan pendidikan (Awaludin, 2017). Oleh karena itu suatu peningkatan kualitas layanan yang terdapat dalam satuan pendidikan bisa tercapai dengan memperhatikan program-program yang sudah ditetapkan dalam kebijakan akreditas yang nantinya mampu memberikan kualitas yang bermutu.

Ketika suatu satuan pendidikan yang menginginkan outputnya bermutu, satuan tersebut juga harus memberikan sesuatu pembaharuan pendidikan yang terus-menerus agar nantinya bisa menghadapi berbagai tantangan sesuai dengan perkembangan. Karena pembaharuan kualitas sekolah dapat dilihat dari berbagai 
segi manajemen sekolah. Selain itu kualitas sekolah juga dipengaruhi oleh beberapa faktor baik dari sekolah itu sendiri maupun dari luar sekolah (Setiyaningsih, 2017).

Pembaharuan pendidikan yang terus-menerus itu bisa dilakukan dengan cara satuan pendidikan mampu mengelola lembaganya dengan cara menerapkan Total Quality Management (TQM). Karena dengan adanya (TQM) dapat mengembangkan program-program yang sudah ditetapkan melalui perencanaanperencanaan dan nantinya bisa menunjukkan keunggulan bagi setiap satuan pendidikan. Dengan demikian suatu satuan pendidikan yang memiliki kelayakan kualitas ditentukan oleh pengelolaan yang bagus dan sesuai dengan rencanarencana yang sudah ditetapkan. Penempatan mutu tersebut tergantung dari apa yang dihasilkan, dipakai, serta anggapan menurut orang lain (Zazin, 2011).

Berdasarkan kajian awal terdapat beberapa penelitian yang serumpun dengan penelitian yang lakukan mengenai penerapan TQM dalam program akreditasi sekolah untuk meningkatkan mutu pendidikan. Penelitian ini lebih banyak mengkritisi dalam pelaksanann proses penerapan TQM. Penjaminan mutu melalui akreditasi sekolah dapat memberikan informasi tentang kelayakan sekolah/madrasah yang dapat dijadikan acuan dalam upaya peningkatan mutu dalam rencana pengembangan sekolah. Akreditasi bisa menjadi pembanding kondisi sekolah dalam kenyataan dengan standar yang sudah ditentukan. Dengan adanya penerapan standar akreditasi secara berkelanjutan mutu pendidikan dapat berkembang.

Melalui akreditasi terdapat hal-hal yang mengarah dalam penjaminan mutu diantaranya dengan adanya proses peningkatan kualitas sekolah, mengetahui gambaran kinerja sekolah yang sebenarnya, sebagai gambaran kelayakan dalam penyelenggara pendidikan serta menjadi alat pembinaan, pengembangan, dan peningkatan mutu pendidikan di sekolah (Awaludin, 2017).

Peningkatan mutu pendidikan sekolah melalui akreditasi harus melibatkan seluruh pelaku pendidikan. Pelibatan berupa upaya untuk melakukan kretifitas dan inovasi baru. Jadi sekolah bisa dikatakan mampu menjalani programprogram yang sudah ditentukan dengan baik dan agar mencapai suatu tujuan yang diinginkan juga harus benar-benar mengoptimalkan persiapan sampai 
dengan pelaksanaannya, tidak hanya mementingkan untuk mendapatkan akreditasi saja akan tetapi benar-benar dikelola dengan baik dan melibatkan seluruh komponen yang terdapat dalam satuan pendidikan tersebut.

Dengan demikian akreditasi sekolah bagi peningkatan kualitas pendidikan cukup memberi warna dengan melengkapi standar-standar yang ada. Standar tersebut sebagai indikator sekolah sebagai lembaga yang benar-benar layak mendapatkan akreditasi, kualitas layanan meningkat, dan semakin baik (Nujumuddin, 2019). Mutu pendidikan merupakan bagian penting sebagai bukti keunggulan serta usaha dari setiap lembaga. Oleh karena itu dalam pencapaian mutu pendidikan tersebut siswa dalam proses belajar mengajar merupakan tolok ukur dari keberhasilan pembelajaran.

Terdapat juga pembahasan pendekatan TQM dalam meningkatkan mutu sekolaah dapat dilakukan melalui strategi perencanaan dengan menyusun visi dan misi sekolah dan melibatkan TPMS (Tim Pengembangan Mutu Sekolah). Implementasi program peningkatan mutu dilakukan Kepala Sekolah dan TPMS yaitu dengan melaksanakan berbagai program sekolah yang telah diprogramkan. Pengawasan peningkatan mutu dilakukan secara berkala dan menyeluruh pada awal dan akhir semester untuk mengetahui ketercapaian kurikulum yang diterapkan. Kemudian evaluasi program dilakukan tidak hanya setiap tahun tetapi dilakukan bulanan. Strategi ini sudah diterapkan dalam peningkatan mutu pendidikan di SMA Negeri 3 Meulaboh (Mardian, 2012).

Penerapan TQM bisa membantu terlaksananya program akreditasi sekolah yang nantinya bisa menjadikan kualitas pendidikan bermutu. Jadi dengan adanya TQM diharapkan bisa mengembangkan program-pogram akreditasi melalui perencanaan-perencanaan dan juga menyelenggarakan pendidikan yang bermutu. Setiap satuan pendidikan yang menginginkan pendidikan yang bermutu juga harus memenuhi standar yang dilakukan melalui kegiatan akreditasi terhadap kelayakan setiap satuan pendidikan.

Adanya program akreditasi sekolah untuk meningkatkan mutu pendidikan harus dibarengi dengan penerapan TQM yang tepat dalam pendidikan. Di dalamnya membahas mengenai bagaimana penerapan TQM, dan bagaimana cara meningkatkan mutu dalam mengembangkan program akreditasi yang sudah 
ditentukan. Penerapan TQM tersebut bertujuan untuk mencapai pendidikan yang bermutu.

\section{B. Metode Penelitian}

Penelitian ini menggunakan metode penelitian riset kepustakaan (Library Research) metode penelitian ini berkenaan dengan metode pengumpulan data pustaka. (Zed, 2004) Metode yang di dalam penelitian ini adalah metode kepustakaan dengan cara menyeleksi, merangkum dan mempertimbangkan masalah sehingga dapat direduksi dan dipaparkan secara sistematis.

Sumber data yang digunakan dalam penelitian ini yaitu berasal dari sumber data primer yang ditulis oleh Jejen Musfah, Edward Sallis, dan Fandy Tjiptono dan juga bersumber dari literature ataupun hasil penelitian yang lain. Dan pengumpulan sumber data tersebut menggunakan metode dokumentasi. Intsrumen penelitian ini berupa pengumpulan data yang terdiri dari teknik dokumentasi. Dokumentasi yang merupakan pencarian dan penelusuran yang bersumber dari buku dan juga literatur-literatur.

Analisis data dalam penelitian ini menggunakan analisis kritis yang dimana analisi ini sifatnya kritis umumnya beranjak dari pandanggan atau nilainilaai tertentu yang diyakini oleh peneliti terkait dalam permasalahan peningkatan mutu pendidikan yang melalui dokumen-dokumen yang berkaitan dengan permasalahan yang peneliti teliti.

\section{Hasil Pembahasan}

\section{Program Akreditasi Sekolah sebagai Upaya Peningkatan Mutu Pendidikan}

Akreditasi dimaknai sebagai suatu proses untuk memberikan penilaian terhadap kualitas menggunakan kriteria mutu yang sudah ditetapkan. Akreditasi dapat diartikan sebagai suatu proses, yang meliputi penilaian profesional untuk mengevaluasi bahwa suatu lembaga pendidikan tersebut memenuhi standar yang sudah ditentukan atau tidak (Prados, 2005).

Proses dari akreditasi yaitu dilakukan dengan cara objektif mengenai kelayakan dan kinerja sekolah. Sekolah dapat memberikan informasi yang dapat dijadikan dasar dalam pengambilan keputusan. Sekolah juga dapat 
berupaya meningkatkan mutu dengan melihat dari evaluasi kegiatan dan akreditasi dilakukan untuk sekolah yang sudah sesuai dengan kesiapan (Hanun, 2015). Adanya akreditasi dapat memetakan mutu pendidikan berdasarkan Standar Nasional Pendidikan serta menjadi acuan dalam upaya peningkatan mutu dan rencana pengembangan sekolah.

Akreditasi sebenarnya tanggung jawab dari lembaga pemerintahan, karena akreditasi bisa sebagai bentuk perlindungan konsumen. Oleh karena itu pemerintah telah menetapkan Badan Akreditasi Sekolah/Madarsah yang berguna sebagai evaluasi mandiri yang menetapkan kelayakan program dalam satuan pendidikan dasar yang mengacu pada standar nasional pendidikan (Awaludin, 2017).

Bentuk adanya akreditasi sekolah yaitu diartikan sebagai proses pengakuan kualifikasi lembaga pendidikan melalui pengukuran dan penilaian kinerja sekolah dengan mengajukan perangkat yang telah ditetapkan. Melalui proses akreditasi sekolah juga harus didukung oleh pemahaman yang sama dan komitmen yang kuat (Suryana, 2015).

Sebagai sarana dalam sebuah pengukuran keberhasilan perkembangan lembaga, akreditasi mempunyai dampak yang bisa membantu sebuah satuan lembaga semakin berkembang sesuai dengan perencanaan dan tujuan yang sudah ditetapkan. Berbicara mengenai akreditasi sebagai acuan kelayakan kinerja sekolah, tentunya juga harus mengetahui kelayakan tersebut bertujuan untuk apa. Kelayakan tersebut diartikan sebagai kualitas satuan pendidikan yang bisa disebut dengan mutu satuan lembaga pendidikan. Akan tetapi dalam sebuah permasalahan bahwasanya akreditasi belum tentu menjamin mutu pendidikan lembaga tersebut semakin meningkat atau bahkan menurun, karena juga terdapat sekolah yang akreditasinya rendah tetapi dalam kenyataannya tidak mempresentasikan rendahnya dalam mutu lembaga tersebut (Karyanto, 2015).

Adanya penetapan akreditasi sekolah diharapkan bisa memaksimalkan program yang nantinya tidak hanya mendapatkan penetapan akreditasi akan tetapi kualitas pendidikannya juga semakin lebih baik (Utiarahman, 2017). Perbaikan tersebut tidak hanya dilakukan pada saat akreditasi saja akan tetapi 
juga dilakukan setelah akreditasi berlangsung. Beberapa sekolah juga melakukan evaluasi setelah selesainya akreditasi dan berkomitmen untuk mempertahankan yang sudah baik dan meningkatkan program-program yang kurang maksimal (Asopwan, 2018). Hasil dari adanya akreditasi sekolah dalam upaya peningkatan mutu pendidikan dapat terlaksana apabila pengelola program sekolah terus berusaha secara maksimal dalam meningkatkan mutu pendidikan.

Sekolah yang mampu mengembangkan program-program akreditasi tentunya tidak lepas dari sebuah perencanaan. Karena pada kenyataanya dalam melakukan akreditasi sekolah tidak berjalan dengan mudah karena banyak permasalahan yang terjadi. Permasalahan yang sering terjadi seperti persiapan yang kurang, bukti fisik yang belum cukup, panduan belum lengkap, dan lainnya. Selain itu sekolah tidak memiliki waktu untuk melakukan evaluasi diri serta kurangnya koordinasi dan komunikasi antar individu maupun tim (Sholihin, 2018).

Peningkatan akreditasi sekolah sangat penting dilakukan dari tahun ke tahun. Pihak Sekolah mempersiapkan dengan baik semua hal yang diperlukan dalam akreditasi sekolah, mulai dari tahap perencanaan, persiapakan sampai dengan pelaksanaan akreditasi sekolah. Dengan adanya akreditasi setiap program-program sekolah bisa berjalan dengan baik dan sesuai dengan tujuan (Novelia, 2019). Hal tersebut bisa berjalan karena akreditasi bisa menjadi sebuah kegiatan yang efektif bagi peningkatan mutu satuan pendidikan.

Akreditasi yang dilakukan dengan cara objektif mengenai kelayakan dan kinerja sekolah dapat memberikan informasi valid. Data ini penting sebagai dasar dalam pengambilan keputusan dan kebijakan. Sekolah dapat berupaya meningkatkan mutu dengan melihat dari evaluasi kegiatan dan hasil penilaian akreditasi (Hanun, 2015).

\section{Pendekatan Total Quality Management dalam Peningkatan Mutu Sekolah}

Total Quality Management (TQM) memiliki arti perbaikan terus menerus yang dapat memberikan data dan informasi dalam peningkatan mutu (Khikmah, 2019). TQM dapat memberikan seperangkat alat praktis kepada 
setiap institusi pendidikan dalam memenuhi kebutuhan, dan harapan saat ini dan masa yang akan datang (Sallis, 2006). TQM mempunyai tujuan memberikan produk dan jasa yang berkualitas untuk memenuhi kebutuhan dan kepuasan pelanggan. TQM mempunyai suatu pendekatan yang dilakukan secara terus menerus dan sudah terkonsep. Jadi sistem TQM tidak hanya dilakukan ketika sudah berjalan saja tetapi harus dilakukan secara berkelanjutan (Mirawan, 2010).

Mutu pendidikan pada dasarnya bisa dikembangkan melalui konsep dari TQM. Oleh karena itu lembaga pendidikan yang bermutu adalah lembaga yang mampu memunculkan kualitas bagus, menghasilkan lulusan dengan kompetensi personal maupun akademik mumpuni (Danim, 2007). Ketika suatu lembaga konsisten menerapakan TQM maka akan terjadi perbaikan yang berkelanjutan. Peningkatan tersebut untuk memenuhi kebutuhan dan harapan sesuai standar akreditasi (Danim, 2007).

Dalam pelaksanaan TQM juga perlu adanya konsep yang mengutamakan pelanggan. Adapun konsep dalam TQM terfokus dalam tiga hal yaitu total, quality, dan management yang mempunyai fokus terhadap kualitas (mutu). TQM juga memiliki karakteristik yang bisa menjadi acuan dalam penerapannya yaitu fokus pada pelanggan, obsesi yang tinggi terhadap kualitas, menggunakan pendekatan ilmiah, berkomitmen jangka panjang, kerjasama tim, berkesinambungan, menyelenggarakan pendidikan dan pelatihan bermutu (Tjiptono \& Diana, 2001). TQM menekankan pada kepuasan pelanggan, keterlibatan karyawan, dan adanya perbaikan yang berkelanjutan. Jadi dengan kinerja yang kondusif akan menghasilkan perubahan yang berkualitas.

Bentuk penerapan Total Quality Management dalam perbaikan kualitas yaitu dengan cara perbaikan secara terus-menerus, menentukan standar mutu, perubahan kultur, perubahan organisasi, dan mempertahankan hubungan dengan pelanggan. Agar cara tersebut dapat berjalan dengan baik maka perlu strategi pelaksanaan yaitu dengan adanya persiapan, perencanaan, dan pelaksanaan (Tjiptono \& Diana, 2001). Karena keberhasilan ataupun kegagalan terhadap penerapan Total Quality 
Management itu semua tergantung pada komitmen dan kerja sama antar semua elemen mulai dari perencanaan sampai dengan puncaknya.

\section{Kesimpulan}

Berdasarkan kajian diatas dapat disimpulkan bahwa penerapan TQM untuk pelaksanaan program akreditasi satuan pendidikan sangat penting. Adanya TQM dalam perbaikan kualitas dapat dilakukan dengan cara perbaikan secara terusmenerus, menentukan standar mutu, perubahan kultur, perubahan organisasi, dan mempertahankan hubungan dengan pelanggan. Upaya tersebut bisa membantu terealisasinya mutu pendidikan yang berkualitas. Dengan penerapan TQM yang baik dalam program akreditasi akan membantu meningkatkan mutu pendidikan sesuai perubahan zaman.

\section{Daftar Pustaka}

Asopwan, D. (2018). Studi Tentang Akreditasi dalam Meningkatkan Produktivitas Sekolah. Indonesian Journal of Education Management and Administration, 2 (2) Awaludin, A. A. (2017). Akreditasi Sekolah Sebagai Suatu Upaya Penjaminan Mutu Pendidikan Di Indonesia. Jurnal SAP, 2 (1)

Danim, S. (2007). Visi Baru Manajemen Sekolah. Bumi Aksara

Fattah, N. (2013). Sistem Penjaminan Mutu Pendidikan. Remaja Rosdakarya

Hanun, F. (2015). Akreditasi Madrasah sebagai Kunci Keberhasilan dalam Pemenuhan Standar Nasional Pendidikan. Jurnal Penelitian Pendidikan Agama dan Keagamaan, 13 (1)

Karyanto, U. G. \& Rahman, A. (2015). Implikasi Akreditasi Sekolah terhadap Peningkatan Mutu Tata Kelola SMK Negeri 1 Oku. Jurnal Manajemen Pendidikan Indonesia, 7 (2)

Khikmah, N., Sunandar, \& Yuliejantiningsih, Y. (2019). Implementasi Total Quality Management dalam Peningkatan Mutu Sekolah di SMA Negeri 1 Slawi Kabupaten Tegal. Jurnal Manajemen Pendidikan, 8(1)

Maghfiroh, L. (2018). Strategi Peningkatan Mutu Pendidikan Madrasah melalui Total Quality Management di Madrasah Ibtidaiyah Wahid Hasyim Yogyakarta. Ta'lim: Jurnal Studi Pendidikan Islam, 1(1)

Mirawan, D. (2010). Penjaminan Mutu Satuan Pendidikan Sebagai Upaya Pengendalian Mutu Pendidikan secara Nasional dalam Otonomi Pendidikan. Education, 4(2)

Musfah, J. (2015). Manajemen Pendidikan. Kencana. 
Novelia I., Azwar, \& Elfitra. (2019). Langkah Progresif Peningkatan Akreditasi Sekolah: Studi SMP di Kota Padang. Jurnal Kajian Keislaman dan Kemasyarakatan, 4 (2)

Nujumuddin. (2019). Dampak Kebijakan Akreditasi terhadap Peningkatan Kinerja Guru Madrasah. Jurnal Penelitian Keislaman, 15 (1)

Prados, J.W., Peterson, G.D., \& Lattuca, L.R. (2005). Quality Assurance of Engineering through Accreditaion The Impact Of Engineering Criteria 2000 and its Globlal Inlfuence. Journal of Engineering Education, 94(1)

Rahman, L. Z. (2020). Upaya Meningkatan Mutu Lembaga Pendidikan Islam melalui Sistem Akreditasi dalam Perspektif Total Quality Management (TQM) di SD Muhammdiyah Karangbendo Bantul. Jurnal Pendidikan dan Studi Keislaman, 10 (2)

RI, U. (2003). Undang-undang Nomor 40. Tentang Sistem Pendidikan Nasional

Sagala, S. (2013). Manajemen Strategik dalam Peningkatan Mutu Pendidikan. Alfabeta

Sallis, E. (2006). Total Quality Management In Education. Divapress

Setiyaningsih, C. D. (2017). Status Akreditasi dan Kualitas Sekolah di Sekolah Dasar Negeri. Jurnal Manajemen dan Supervisi Pendidikan, 1 (2)

Sholihin, E. N. C., Bafadal, I., \& Sunandar, A. (2018,). Pengelolaan Persiapan Akreditasi Sekolah. Jurnal Administrasi dan Manajemen Pendidikan, 1 (2)

Suryana, A. (2005). Akreditasi, Sertifikasi dan Upaya Penjaminan Mutu. Jurnal Administrasi Pendidikan, 3(2). https://doi.org/10.17509/jap.v3i2.6116

Tjiptono, F. \& Diana, A. (2001). Total Quality Management. Andi Offset

Utiarahman, P. (2017). Manajemen Program Akreditasi Pada Sekolah Menengah Pertama Negeri di Kabupaten Boalemo. Jurnal Riset dan Pengembangan Ilmu Pengetahuan, 2 (1)

Zazin, N. (2011). Gerakan Menata Mutu Pendidikan. Arruzz Media

Zed, M. (2004). Metode Penelitian Kepustakaan. Yayasan Obor Indonesia 